\title{
A novel, integrated in vitro carcinogenicity test to identify genotoxic and non-genotoxic carcinogens using human lymphoblastoid cells
}

\author{
Eleanor C. Wilde ${ }^{1} \cdot$ Katherine E. Chapman $^{1}$ (D) Leanne M. Stannard ${ }^{1} \cdot$ Anna L. Seager $^{1} \cdot$ Katja Brüsehafer $^{1}$. \\ Ume-Kulsoom Shah ${ }^{1} \cdot$ James A. Tonkin $^{2} \cdot$ M. Rowan Brown ${ }^{2} \cdot$ Jatin R. Verma $^{1} \cdot$ Ann T. Doherty ${ }^{3}$. \\ George E. Johnson ${ }^{1} \cdot$ Shareen H. Doak ${ }^{1} \cdot$ Gareth J. S. Jenkins $^{1}$
}

Received: 24 July 2017 / Accepted: 24 October 2017 / Published online: 6 November 2017

(c) The Author(s) 2017. This article is an open access publication

\begin{abstract}
Human exposure to carcinogens occurs via a plethora of environmental sources, with $70-90 \%$ of cancers caused by extrinsic factors. Aberrant phenotypes induced by such carcinogenic agents may provide universal biomarkers for cancer causation. Both current in vitro genotoxicity tests and the animal-testing paradigm in human cancer risk assessment fail to accurately represent and predict whether a chemical causes human carcinogenesis. The study aimed to establish whether the integrated analysis of multiple cellular endpoints related to the Hallmarks of Cancer could advance in vitro carcinogenicity assessment. Human lymphoblastoid cells (TK6, MCL-5) were treated for either 4 or $23 \mathrm{~h}$ with 8 known in vivo carcinogens, with doses up to $50 \%$ Relative Population Doubling (maximum $66.6 \mathrm{mM}$ ). The adverse effects of carcinogens on wide-ranging aspects of cellular health were quantified using several approaches; these included chromosome damage, cell signalling, cell morphology, cell-cycle dynamics and bioenergetic perturbations.
\end{abstract}

Eleanor C. Wilde and Katherine E. Chapman contributed equally to the manuscript.

Electronic supplementary material The online version of this article (http://doi.org/10.1007/s00204-017-2102-y) contains supplementary material, which is available to authorized users.

Katherine E. Chapman

K.E.Chapman@swansea.ac.uk

1 In Vitro Toxicology Group, Institute of Life Science 1, Singleton Campus, Swansea University Medical School, Swansea University, Swansea SA2 8PP, UK

2 College of Engineering, Bay Campus, Swansea University, Swansea SA1 8EN, UK

3 AstraZeneca, Discovery Safety, DSM, Darwin Building, Cambridge Science Park, Milton Road, Cambridge CB4 0WG, UK
Cell morphology and gene expression alterations proved particularly sensitive for environmental carcinogen identification. Composite scores for the carcinogens' adverse effects revealed that this approach could identify both DNAreactive and non-DNA reactive carcinogens in vitro. The richer datasets generated proved that the holistic evaluation of integrated phenotypic alterations is valuable for effective in vitro risk assessment, while also supporting animal test replacement. Crucially, the study offers valuable insights into the mechanisms of human carcinogenesis resulting from exposure to chemicals that humans are likely to encounter in their environment. Such an understanding of cancer induction via environmental agents is essential for cancer prevention.

Keywords Carcinogenesis - In vitro · Genotoxicity · Multiple-endpoint $\cdot$ Carcinogenicity testing

\section{Introduction}

Cancer is the second leading cause of mortality worldwide, with the number of new cases projected to rise by $70 \%$ over the next two decades (Stewart and Wild 2017). It has been demonstrated that 70-90\% of human cancers are induced via exposure to environmental agents (Wu et al. 2016). Common routes of exposure to chemical carcinogens include the consumption of alcoholic beverages, tobacco smoking and occupational exposure.

Cancer may be initiated via both genotoxic and nongenotoxic mechanisms (Hanahan and Weinberg 2000, 2011). Most identified carcinogens fall within the initial group of genotoxic carcinogens (GCs), these triggering DNA mutation or chromosomal aberration (Hernandez et al. 2009). However, non-genotoxic carcinogens 
(NGCs), which constitute 10-20\% of carcinogens (Bartsch and Malaveille 1989), demonstrate broader mechanistic variety, altering epigenetics, the endocrine system, apoptotic signalling, cell proliferation, and/or gap-junctional intercellular communication (Melnick et al. 1996; Uehara et al. 2008; Williams 2001). Furthermore, simultaneous alteration of multiple pathways is often required to prompt non-genotoxic oncogenesis (Guyton et al. 2009). Therefore, to understand an unknown carcinogenic mechanism, whether genotoxic or non-genotoxic, multiple-endpoint analysis is required. The eventual result, cancer development, combines uncontrolled cellular proliferation with genome instability, angiogenesis, and metastasis to distant tissues. Such characteristics have been defined as "Hallmarks of Cancer" (Hanahan and Weinberg 2000).

Carcinogenicity testing is a crucial aspect of compound development and safety assessment in pharmaceutical, food and agricultural industries. Such testing includes short-term in vitro assays, short-term in vivo assays, and the 2-year rodent bioassay (Kirkland et al. 2005). Banning of in vivo cosmetics testing in 2013 has increased dependence on in vitro tests, contributing to expense, time and ethical benefits. It is argued, particularly as part of Toxicity Testing in the 21st Century (Adeleye et al. 2015; Council 2007), that the in vitro shift may also improve human relevance: animal models often fail to represent human physiology, genetics and metabolism (Long 2007). Furthermore, recognition of the importance of the 3Rs (Reduction, Replacement and Refinement of animals in research) Principle is increasing. Development of more sophisticated in vitro assays is, therefore, key to future compound development.

Genotoxicity assays represent preliminary carcinogenicity testing, with the standard in vitro genotoxicity battery including the Ames test, micronucleus assay and the chromosomal aberration assay (Muller et al. 1999). Despite this battery achieving high sensitivity, factors such as variation between cell lines, time points, and incomplete compound metabolism reduce the specificity of results (Kirkland et al. 2005). An additional inadequacy of in vitro carcinogenicity assessment is the lack of approved tests for the identification of non-genotoxic carcinogens. For example, one currently available approach is the use of Cell Transformation Assays (CTAs), which utilises the phenotypic transformation of stem cells as a marker of carcinogenicity (Kerckaert et al. 1996). However, disadvantages include these assays' subjectivity, qualitative results and lack of mechanistic insight. Cells used are often derived from rodent embryos (e.g., Syrian hamster embryo, mouse BALBc 3T3 and C3H/10T cells), and so it is unclear whether these tests can be considered to be true in vitro tests, resulting in 3Rs-related implications. Therefore, it is clear that more informative in vitro tests with greater specificity are urgently required.
The objective of this study was to improve the in vitrobased detection of carcinogenic mechanisms, including differentiation between GCs and NGCs by combining multiple cellular and molecular endpoints.

The test compounds were selected for their broad range of carcinogenic mechanisms (Table 1), allowing the applicability of the approach for identifying carcinogens to be assessed. The genotoxicity and mutagenicity of alkylating agents methyl methanesulfonate (MMS) and $N$-methyl$N$-nitrosourea (MNU) is well established, with these producing differing profiles of methyl DNA adducts (Beranek 1990; Doak et al. 2007). Pro-oxidant hydrogen peroxide $\left(\mathrm{H}_{2} \mathrm{O}_{2}\right)$ produces lesions such as 8-oxoguanine (Finnegan et al. 2010), whereas acetaldehyde induces lesions such as N2-ethyl-2'-deoxyguanosine (Brooks and Theruvathu 2005).

The NGCs were also selected for their diverse mechanisms of carcinogenesis; 2,3,7,8-tetrachloro-dibenzo-paradioxin (TCDD) and bis-2-ethylhexyl phthalate (DEHP) are both well-known endocrine disruptors and tumour promoters (Bock and Köhle 2005; Caldwell 2012; Casals-Casas and Desvergne 2011). Heavy metal compound nickel chloride $\left(\mathrm{NiCl}_{2}\right)$ induces oxidative stress. The carcinogenic mechanism of methyl carbamate (MC) is less well-characterised, although MC may elicit effects via bioaccumulation (Ioannou et al. 1988).

The compounds' relevance to human environmental exposure was a further justification (Table 1). Three of the chemicals, MMS, DEHP and MC, are also included on a recommended list of genotoxic and non-genotoxic chemicals for the assessment of the performance of new or improved genotoxicity tests (Kirkland et al. 2016).

Integrating multiple endpoints alongside genotoxicity testing was expected to provide considerably more mechanistic information to support the testing paradigm. To achieve this, the analysis of known in vivo carcinogens was performed (Table 1), with endpoints including micronucleus induction, cell-cycle alterations, cell signalling abnormalities, mitochondrial perturbations and cell morphology alterations. These endpoints cover 4 of the 6 original cancer hallmarks (Hanahan and Weinberg 2000). Results from this study have been integrated to define both genotoxic and nongenotoxic mechanisms with the future objective of developing a fully multiplexed in vitro assay for high-throughput analysis of carcinogenic potential of unknown agents.

\section{Materials and methods}

\section{Chemicals}

Test chemicals were purchased from Sigma-Aldrich (Haverhill, UK), with the exception of MNU (Fluorochem, Pasadena, CA, USA) and TCDD (LGC Standards, Middlesex, 
UK), and stored according to the manufacturer's instructions. $\mathrm{H}_{2} \mathrm{O}_{2}, \mathrm{MMS}, \mathrm{MC}$ and $\mathrm{NiCl}_{2}$ were dissolved/diluted in $\mathrm{dH}_{2} \mathrm{O}$, whereas MNU and DEHP were dissolved/diluted in dimethyl sulfoxide (DMSO) (Thermo Fisher Scientific, Loughborough, UK).

\section{Cell culture}

The human lymphoblastoid cell lines, TK-6 and MCL-5 (ECACC), were cultured in RPMI 1640 Medium (Life Technologies, Paisley, UK) supplemented with $10 \%$ donor horse serum and 1\% L-glutamine (both Life Technologies). Hygromycin B was used to supplement MCL-5 cultures (TCDD only) to support uptake of plasmids. The cells were maintained in culture between $1 \times 10^{5}$ and $1 \times 10^{6}$ cells/ $\mathrm{ml}$. For all studies, cells were seeded at a density of $1 \times 10^{5}$ cells $/ \mathrm{ml}$ and cultured for $24 \mathrm{~h}$ prior to chemical treatment $\left(37^{\circ} \mathrm{C}, 5 \% \mathrm{CO}_{2}\right)$.

\section{Cytokinesis blocked micronucleus assay}

Chromosome damage was analysed using the cytokinesis blocked micronucleus (CBMN) assay. The protocol for Metafer analysis is presented in (Seager et al. 2014). Timepoints used were either $4 \mathrm{~h}$ treatment $+23 \mathrm{~h}$ recovery, or $23 \mathrm{~h}$ treatment $+23 \mathrm{~h}$ recovery. A total of 9000 binucleate cells were scored per treatment per replicate. Relative population doubling (RPD) (\%) (Fellows et al. 2008; Lorge et al. 2008) was measured in parallel, with $<50 \%$ reduction in RPD relative to the vehicle control aimed for, in line with OECD requirements.

\section{Protein isolation and immunoblotting}

To investigate $\mathrm{p} 53$ and phospho-p53 expression following treatment, protein isolation and immunoblotting were performed. The method followed is detailed in (Brusehafer et al. 2014).

\section{mRNA microarrays}

mRNA microarray chip technology (Illumina, Cambridge, UK) was used to initially measure genome-wide transcriptomic changes induced by MMS, DEHP and MC at 4 and $23 \mathrm{~h}$. A shortlist of genes for further qRT-PCR analysis was generated (Supplementary File 1). RNA was extracted from treated cultures using the RNeasy Mini Kit (Qiagen, Manchester, UK) following the manufacturer's protocol. Microarray analysis was performed by Central Biotechnology Services (Cardiff University, Cardiff, UK) using an Illumina platform bead express model, with a total of 25,202 Illumina probes for known genes. Genes selected for follow-up qRT-PCR analysis were Cyclin-dependent kinase inhibitor 
1A (CDKN1A), Choline kinase alpha (CHKA) and Serine/ threonine protein kinase $(S G K l)$.

\section{Gene expression analysis}

qRT-PCR was completed for the aforementioned genes; the protocol is detailed in (Brusehafer et al. 2014). Primer sequences: CDKN1A Forward: 5'GACTCTCAGGGTCGA AAACG3', Reverse: 5'GGATTAGGGCTTCCTCTTGG3'. CHKA Forward: 5'TGCAGATGAGGTCCTGTAATAAAG A3', Reverse: 5'TTTTGGCCCAAGTGACCTCT3'. SGK1 Forward: 5'GAACCACGGGCTCGTTTCTAT3', Reverse: 5'GCAGGCCATACAGCATCTCAT3'. ACTB Forward: 5'GATGGCCACGGCTGCTTC3', Reverse: 5'TGCCTC AGGGCAGCGGAA3'. A CFX Connect Real-time System and CFX Manager software (both BioRad, Oxford, UK) were used.

\section{Cell-cycle analysis}

Flow cytometry was used to assess nucleated cells in G1, S and G2, where samples were processed using the In Vitro MicroFlow Micronucleus Analysis Kit (Litron Laboratories, Rochester, NY, USA), as per the manufacturer's instructions. Samples were analysed using the BD Facs Aria Flow Cytometer (BD Biosciences, Wokingham, UK), with FacsDiva software (BD Biosciences). Appropriate gating was applied to determine the cell-cycle phase. A total of 36,000 events were analysed across 3 replicates per dose.

\section{Cell morphology analysis}

Following treatment, cells were washed with PBS, fixed for $15 \mathrm{~min}$ with $4 \%$ paraformaldehyde and stained for $30 \mathrm{~min}$ with $2.5 \mu \mathrm{g} / \mathrm{ml}$ Hoechst 33,342 (Life Technologies). Brightfield and Hoechst images were acquired utilising the INCell Analyzer 2000 or 2200 (144 fields/well) (GE Healthcare, Cardiff, UK). Image analysis was performed with Matlab Version 7.12.0 (R2011a). Following this, an equal number of cell and nuclear area results were selected from a group of control replicates. These control groups were segregated depending on experimental conditions, vehicle and cell type. The smallest $20 \%$ of the population were then classified as 'Lowest', the next $20 \%$ as 'Low' and so on to classify 'Medium', 'High' and 'Highest' cellular/nuclear area thresholds (these being quintiles) (Supplementary File 2).

\section{Bioenergetics studies}

The Seahorse Bioanalyzer (Agilent, Cheadle, UK) was used to measure bioenergetic flux in control and treated samples, to establish whether chemicals influenced this endpoint. Seahorse microplates (Agilent) were coated using CellTak reagent (Corning, UK). Cells pre-treated with the appropriate chemical for 4 or $23 \mathrm{~h}$ were transferred to coated microplates (400,000 cells/well) $1 \mathrm{~h}$ prior to assay commencement, with gentle centrifugation at $20 \times g$ to aid adhesion. Unbuffered Seahorse medium adjusted to $\mathrm{pH} 7.5$ (Agilent) was used. The plate was then transferred to a non- $\mathrm{CO}_{2}$ incubator for $25 \mathrm{~min}$ prior to addition of $425 \mu \mathrm{l}$ medium and then incubated for a further $35 \mathrm{~min}$ to promote equilibration. Following routine calibration of the machine, oxygen consumption rate $(\mathrm{OCR})$ and extracellular acidification rate (ECAR) were measured simultaneously using the $\mathrm{XF}^{\mathrm{e}} 24$ Seahorse Bioanalyzer to assess basal versus drug-induced perturbations.

\section{$\mathrm{ToxPi}^{\mathrm{TM}}$ graphical user interface}

The Toxicological Prioritization Index (ToxPi ${ }^{\mathrm{TM}}$ ) Graphical User Interface (GUI) is a publically available visualization tool developed at the University of North Carolina that enables the integration of multiple sources of evidence on exposure and/or safety (Reif et al. 2010, 2013). The software may be accessed via http://comptox.unc.edu/toxpi.php. Within the pie chart, the length of the "slice" radius was proportional to the magnitude of the change relative to the vehicle control. The concentration of chemical inducing a $50 \%$ reduction in RPD relative to the vehicle control, or the highest concentration administered, was used to generate fold-change values relative to the control. Slices of the pie chart were weighted according to the nature of the endpoint. Specifically, slice weightings were allocated depending on the number of endpoints measured by a single technique. All individual techniques (e.g., qRT-PCR, cell-cycle analysis) were weighted equally. Therefore, if one technique measured two or three endpoints, the sum of the weightings of these individual endpoints would be equal to the techniques with a single measured endpoint (i.e., CBMN assay and Seahorse). The square root of all values (with the exception of cell and nuclear area) was taken and scores were scaled sufficiently to enable clear "slice" visualisation for endpoint groups.

\section{Statistical analysis}

Three biological replicates (except where indicated) were performed on separate days, with separate vials of cells/chemicals. Error bars represent standard deviation. Dose-Response Modelling with Smoothing Splines (DRSMOOTH, Mutait.org), was used to perform the statistical analysis, to identify statistically significant increases or decreases for treated samples relative to the vehicle control (Avancini et al. 2016). A mean-centering approach was used for the qRT-PCR data (Willems et al. 2008) prior to statistical analysis using DRSMOOTH. Outcomes of $p \leq 0.05$ for two-sided tests were deemed statistically 
significant. For the analysis of data generated by the Seahorse Bioanalyzer, SPSS was used to perform hierarchical cluster analysis.

\section{Results}

The study of the mechanisms by which chemical compounds in the environment may induce cancer is essential. Many in vitro-based genotoxicity tests currently only assess a single genotoxic endpoint, thus increasing the possibility of misleading predictive data. Negative results in genotoxicity and mutation-based assays for chemicals do not always equate to the chemicals being non-carcinogens, considering that a subset of carcinogens are nongenotoxic. Therefore, it is emerging that the use of more sophisticated, multiple-endpoint in vitro approaches will better inform safety assessment while minimizing laboratory animal use. Multiple endpoints allow a holistic overview of chemicals' effects on cells, leading to greater mechanistic understanding for both genotoxic and nongenotoxic carcinogens. Here, a novel integrated test strategy was developed using a variety of carcinogenicityassociated endpoints.

\section{The GCs caused genotoxicity}

Genotoxicity induction was measured using a high-powered CBMN assay (Fig. 1). Cells were treated with test chemical for $4 \mathrm{~h}$ ( $+23 \mathrm{~h}$ recovery) initially to identify no-observed effect levels (NOELs) and lowest observed effect levels (LOELs) for micronucleus ( $\mathrm{MN}$ ) dose-responses. If no significant increases in genotoxicity (i.e., LOELs) were observed after $4 \mathrm{~h}+23 \mathrm{~h}, 23 \mathrm{~h}$ treatment was performed ( $+23 \mathrm{~h}$ recovery). $\mathrm{H}_{2} \mathrm{O}_{2}$ was the only positive chemical after $4 \mathrm{~h}$ (Fig. 1c). The three other GCs, acetaldehyde, MMS and MNU, did not produce significant changes in genotoxicity after $4 \mathrm{~h}$ (data not shown). At $23 \mathrm{~h}$, however, all of these chemicals caused $\mathrm{MN}$ induction at concentrations of $\geq 500$, 6.4 and $2.9 \mu \mathrm{M}$, respectively (Fig. 1).

No NGCs tested, DEHP, $\mathrm{MC}, \mathrm{NiCl}_{2}$, and TCDD, induced significant $\mathrm{MN}$ increases at any test concentrations after 4 or $23 \mathrm{~h}$. As TCDD is known to induce enzymes such as the Cytochrome P450 s (Hukkanen et al. 2000), it was tested using the metabolically competent MCL-5 cell line (Fig. 1h); here, no significant increases in $\mathrm{MN}$ frequency were observed $(p>0.05)$. MC was the only chemical not to approach $50 \%$ cytotoxicity. Dose selection for MC was performed based on literature, hence the maximum concentration exceeded the recommended $10 \mathrm{mM}$ (Kim et al. 2005; Kwon et al. 2007; Mitchell et al. 1997).

\section{p53 and phospho-p53 increased in response to all genotoxic and one non-genotoxic chemical}

p53 is an important node in the DNA Damage Response (DDR) with a central role in carcinogenesis (Banin et al. 1998). p53 and phospho-p53 protein levels were assessed using Western blotting (immunoblotting) and the relevant bands on images quantified using densitometry (Fig. 2). For GCs, MNU and $\mathrm{H}_{2} \mathrm{O}_{2}$ induced p53 and phospho-p53 at concentrations above their respective genotoxicity LOELs (Fig. 2c, d). MMS and acetaldehyde also increased p53 and phospho-p53, although these changes were non-significant (Supplementary File 3). As Western blotting is only semiquantitative, it is plausible that such changes indicate true biological effects, despite lacking significance. Treatment with the $\mathrm{NGC} \mathrm{NiCl}_{2}$ also elevated p53 levels, despite this chemical not inducing genotoxicity (Fig. 1). $\mathrm{NiCl}_{2}$, however, did not cause a dose-dependent increase, with only $100 \mu \mathrm{M}$ increasing p53 abundance. Interestingly, $\mathrm{NiCl}_{2}$ was the only chemical tested to significantly induce reactive oxygen species (ROS), (Supplementary File 4), possibly explaining this unusual result. DEHP, MC and TCDD did not cause significant changes in p53 or phospho-p53 protein abundance (Supplementary File 3).

\section{Carcinogens altered p21, CHKA and SGK1 mRNA expression}

Whole-genome RNA microarrays were used to determine a small panel of target genes altered by DEHP, MC and MMS for further, more detailed gene expression studies by qRT-PCR. Following microarray analysis, three "carcinogenesis biomarker" genes were taken forward for further investigation: $C D K N 1 A, C H K A$ and $S G K 1$ (highlighted in Supplementary File 1). $C D K N 1 A$ encodes p $21^{\mathrm{Cip} / \mathrm{Waf}}$; due to its relevance to cancer, this gene was selected independently of the microarray data. The other two genes, $\mathrm{CHKA}$ and $S G K 1$, were selected based on the criteria outlined in Supplementary File 1, Tab 2. CHKA is known to be overexpressed in human tumours (de Molina et al. 2002), while $S G K 1$ regulates survival and growth in colorectal cancers (Lang et al. 2010).

Two GCs, MMS and MNU, induced clear dose-dependent increases in mRNA transcribed from the p21 gene (Fig. 3c, d). Acetaldehyde stimulated a biphasic dose-response, with an increase at $250 \mu \mathrm{M}$, followed by a decrease at $1000 \mu \mathrm{M}$. Indeed, all GCs increased p21 expression, despite levels of p21 induced by $\mathrm{H}_{2} \mathrm{O}_{2}$ lacking significance. It was noted that acetaldehyde, MMS and MNU produced significant increases in expression of p21-encoding mRNA at concentrations below the MN LOELs (Fig. 1), a phenomenon not observed with Western blotting for p53 activation. MMS and acetaldehyde both significantly altered $C H K A$ gene 


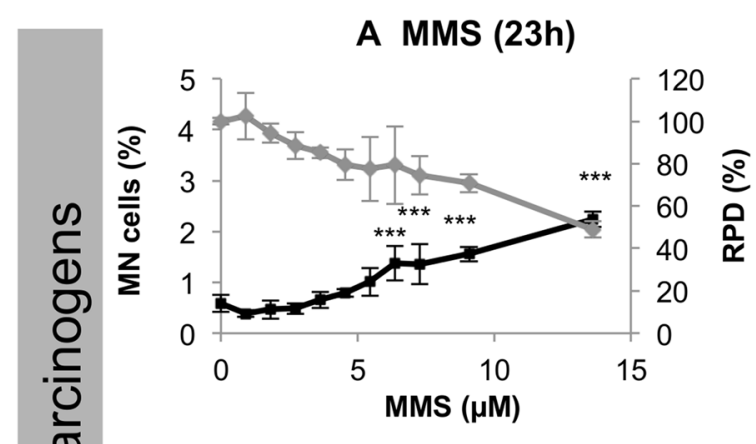

B Acetaldehyde (23h)

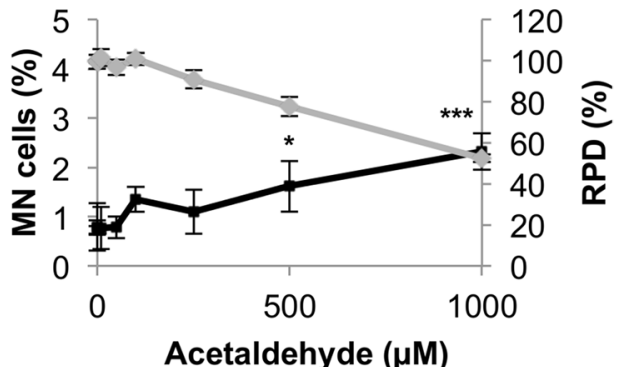

D MNU (23h)

C $\mathrm{H}_{2} \mathrm{O}_{2}(4 \mathrm{~h})$
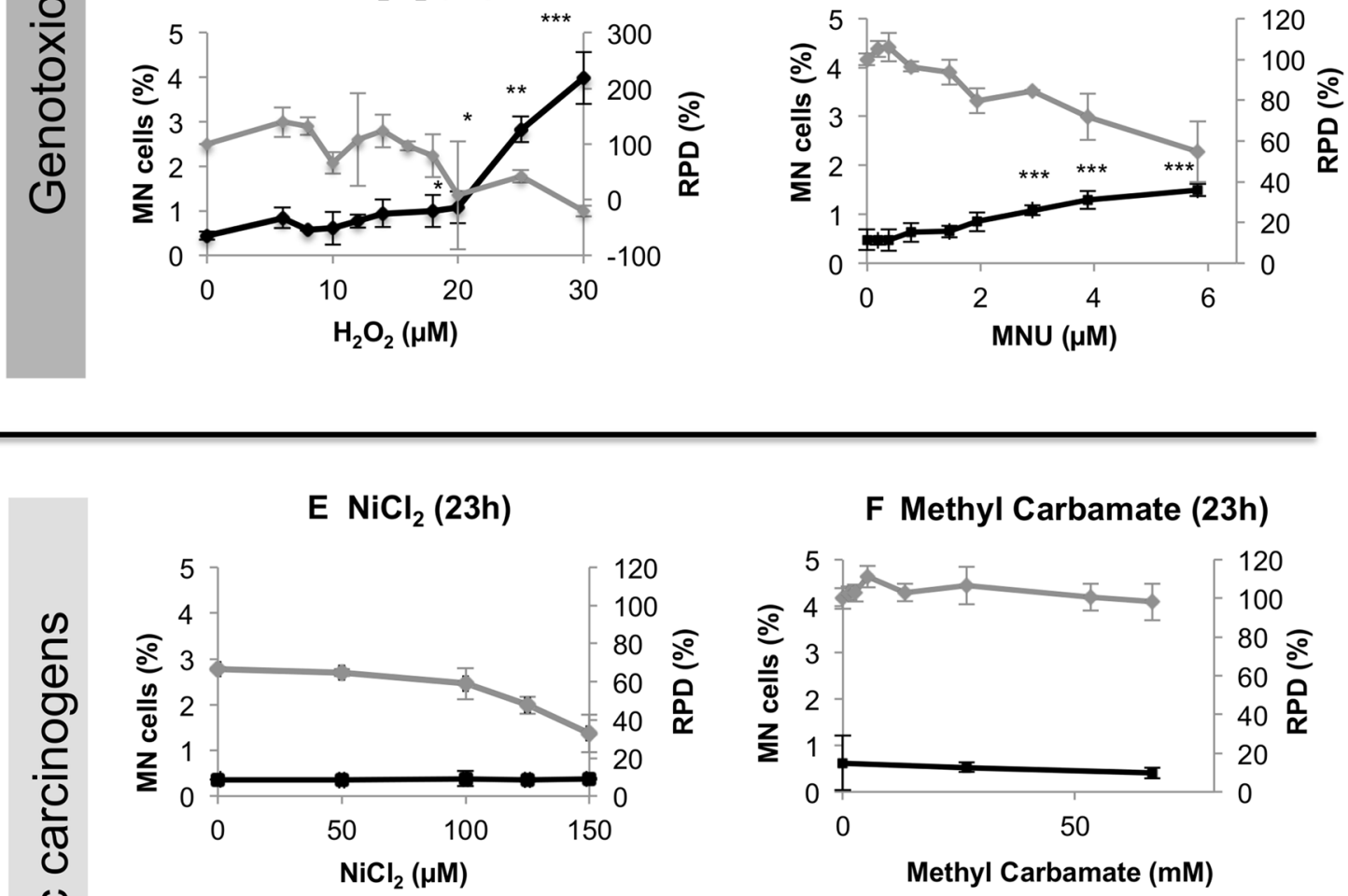

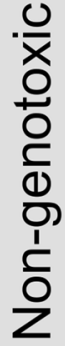

\section{G DEHP (23h)}

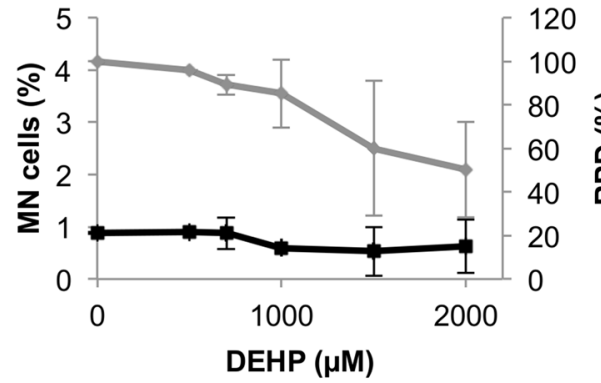

$\longrightarrow$ Average $\mathrm{MN} \longrightarrow$ Average RPD

Fig. 1 The CBMN assay (4 or $23 \mathrm{~h}$ exposure $+23 \mathrm{~h}$ recovery) was used to determine whether test compounds were genotoxic. Micronucleated cells (\%) (black lines) and Relative Population Doubling (RPD) (\%) (grey lines) data are displayed for eight chemicals $(n=3$ for $\mathbf{a}-\mathbf{d}, n=2$ for $\mathbf{e}-\mathbf{h})$. Data for NGCs are presented in duplicate due to two replicates being sufficient to confirm the lack of $\mathrm{MN}$-induction for these chemicals. Statistically significant changes in percentage cells relative to the vehicle control are denoted by $*$, where $* p \leq 0.05$, $*^{*} p \leq 0.01$ and $* * * p \leq 0.001$. For RPD, a Beckman Coulter Counter was used to count cells prior to dosing and following the recovery period 
A

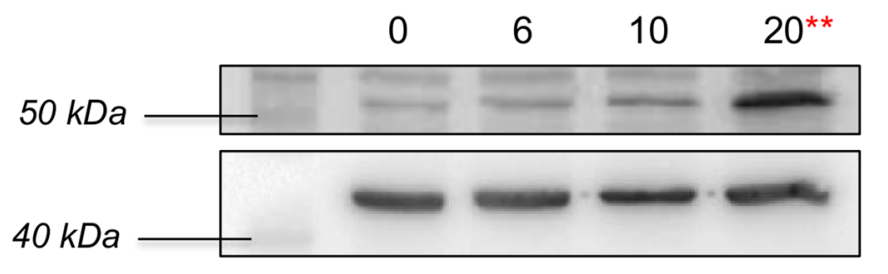

$\mu \mathrm{M}$

B-actin

B
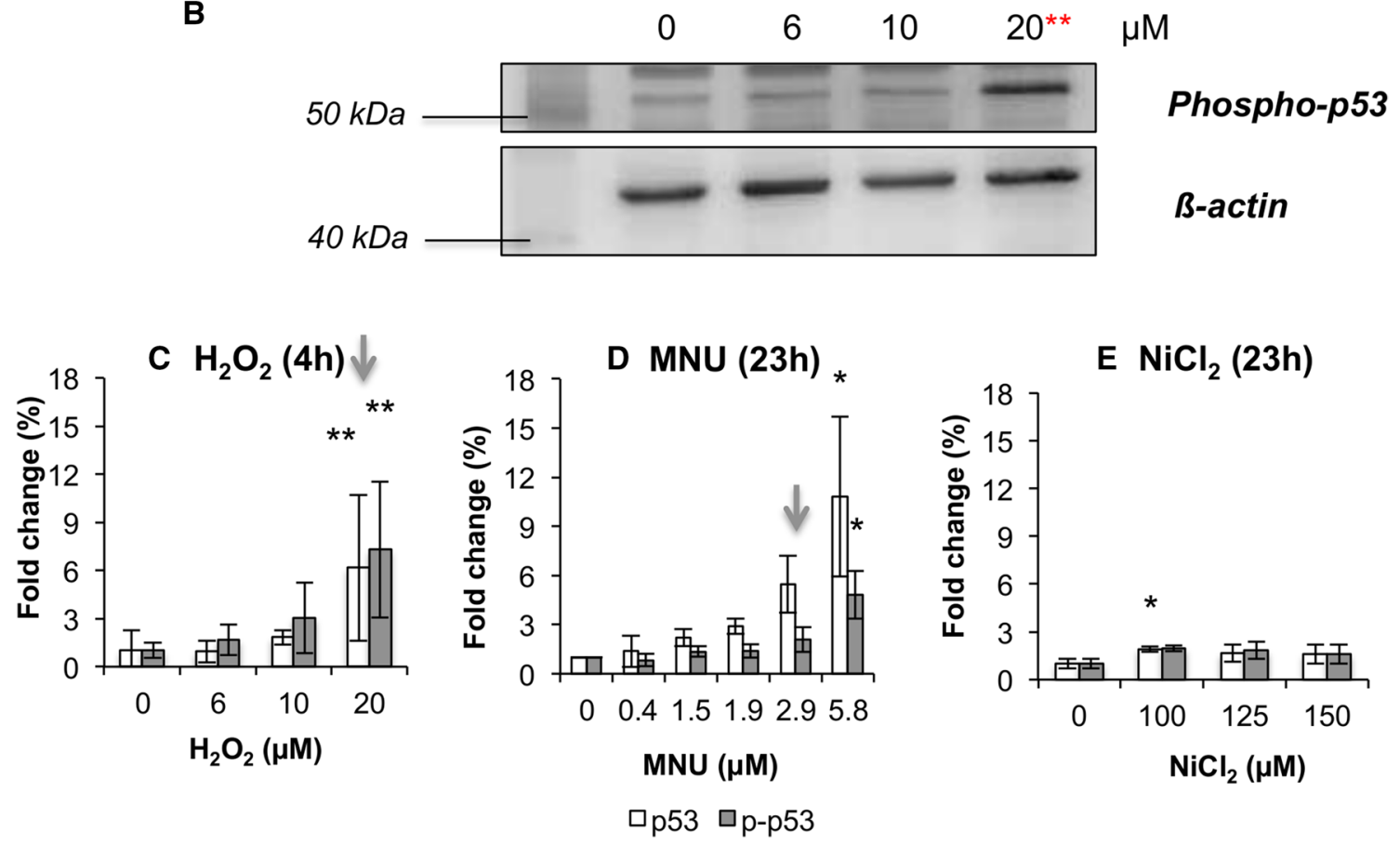

Fig. 2 p53 and phospho-p53 expression as determined by Western blotting for 4 or $23 \mathrm{~h}$ exposure. a, b Representative examples of blot images for p53, phospho-p53 (Both $53 \mathrm{kDa})$ and $\beta$-actin $(45 \mathrm{kDa})$. These examples were from $\mathrm{H}_{2} \mathrm{O}_{2}$ treatment. c-e Densitometry graphs are presented for chemicals that caused significantly altered expression of p53 and/or phospho-p53 $(n=3)$. Statistically signifi-

expression relative to the control (Fig. 3, Supplementary File 3). $\mathrm{H}_{2} \mathrm{O}_{2}$ and $\mathrm{MNU}$ significantly altered $S G K 1$ expression at the highest test concentrations (Fig. 3). With the exception of MMS, all GCs increased SGK1 mRNA expression above control levels (Fig. 3, Supplementary File 3).

NGCs also demonstrated a capacity to alter gene expression (Fig. 3e-h). Three NGCs significantly altered p21 mRNA expression: DEHP, $\mathrm{NiCl}_{2}$ and $\mathrm{MC}$ (Fig. 3). $\mathrm{NiCl}_{2}$ produced a clear dose-dependent increase in p21 mRNA (Fig. 3e). Interestingly, MC significantly reduced both p21 and SGK1 mRNA levels, in contrast to the GCs that increased their expression. Two NGCs, MC and TCDD, significantly altered CHKA expression (Fig. 3). However, all NGCs increased CHKA mRNA expression (Supplementary File 3). MC and TCDD were also the only NGCs to significantly alter $S G K 1$ levels. In summary, all eight chemicals cant changes in fold change expression are denoted by red *, where $* p \leq 0.05, * * p \leq 0.01$ and $* * * p \leq 0.001$. Arrows above specific concentrations correspond to the MN LOEL, or concentration nearest to the LOEL, for the carcinogens (Fig. 1), where applicable (colour figure online)

caused statistically significant dysregulation of at least one of the genes tested.

\section{Four test chemicals induced arrest at G2 phase of the cell-cycle}

As the cell-cycle is a crucial link to the cancer hallmark of uncontrolled proliferation, the distribution of nucleated cells in G1, S and G2 cell-cycle phases immediately following 4 or $23 \mathrm{~h}$ treatments was measured using flow cytometry (Fig. 4). All GCs stimulated statistically significant and, in the case of MMS and acetaldehyde, dose-dependent, increases in cells in the $\mathrm{G} 2$ phase after $23 \mathrm{~h}$, indicating $\mathrm{G} 2$ arrest (Fig. 4a-d). These G2 increases were accompanied by statistically significant reductions in the two other cellcycle categories, $\mathrm{G} 1$ and $\mathrm{S}$ phase. The $\mathrm{GC}_{2} \mathrm{H}_{2}$ did not induce any statistically significant changes in the cell-cycle 


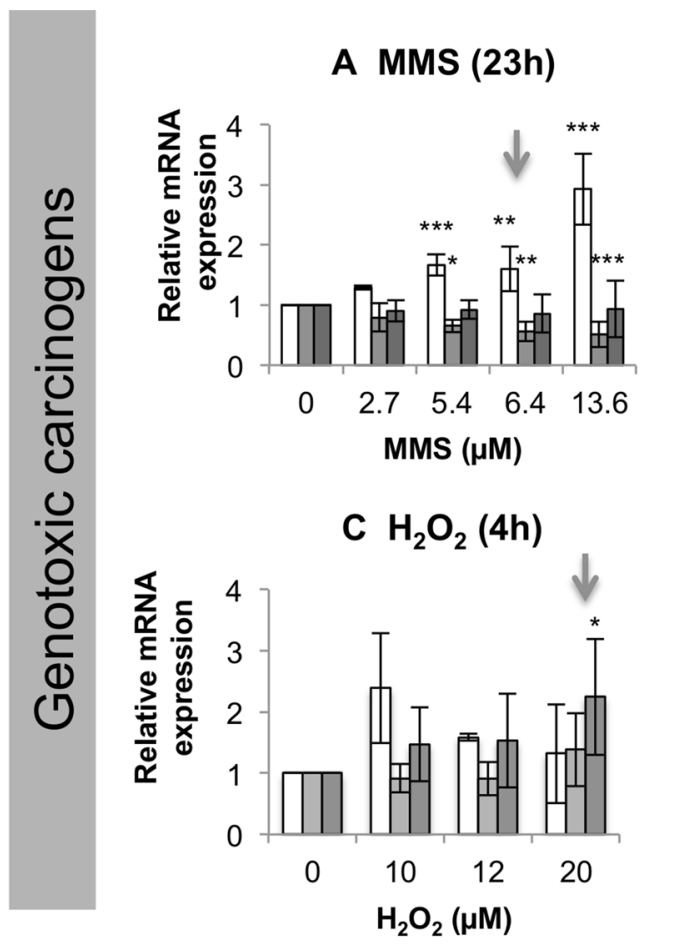

B Acetaldehyde (23h)

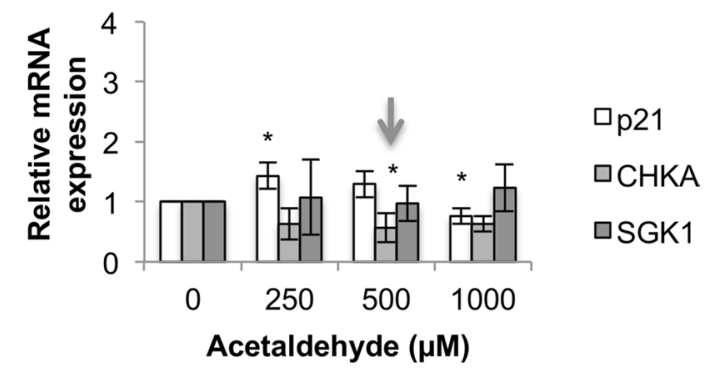

D MNU (23h)
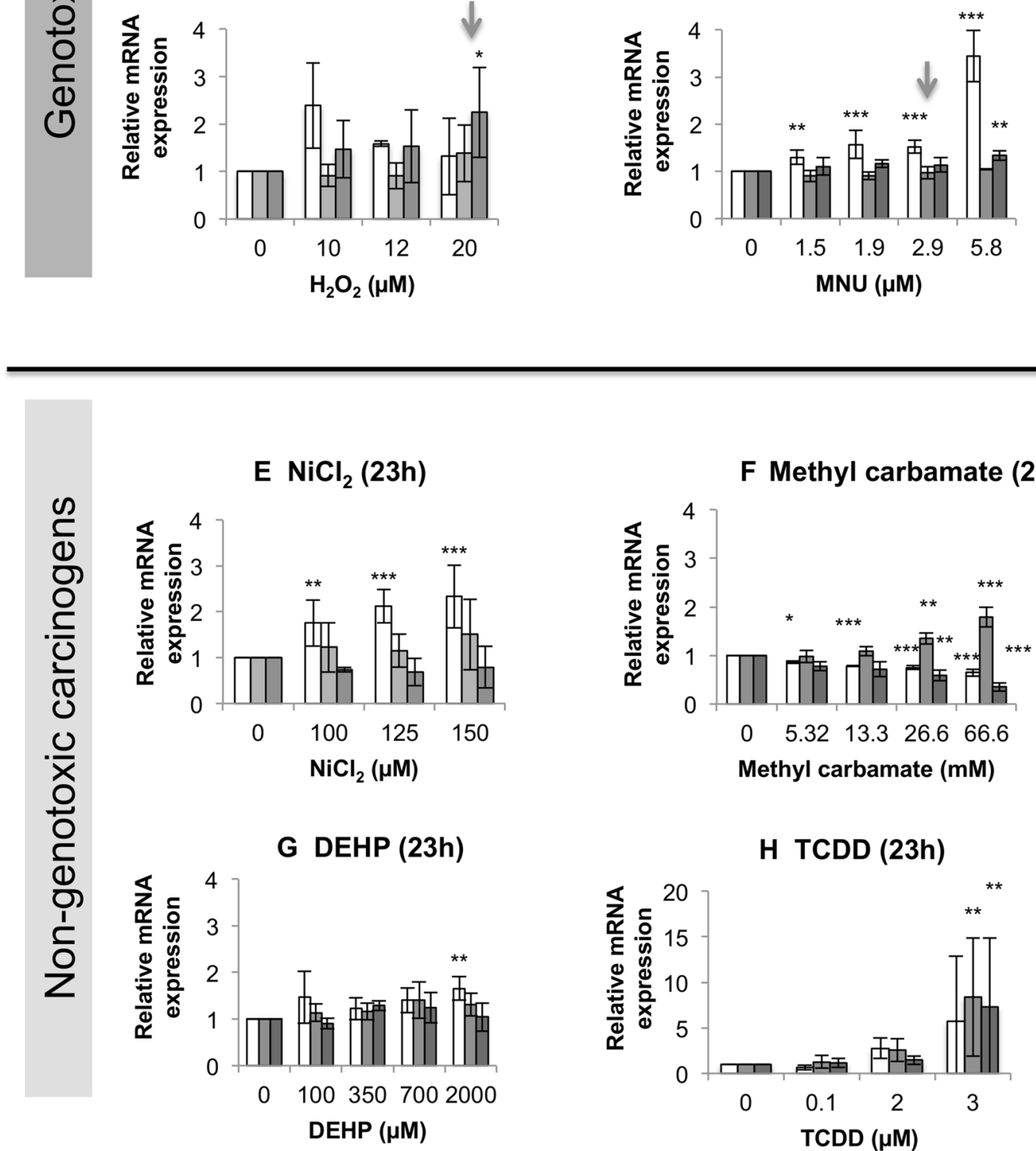

Fig. 3 Relative expression of mRNA of the CDKN1A,CHKA and $S G K 1$ genes as determined by qRT-PCR $(n \geq 3)$ for 4 or $23 \mathrm{~h}$ exposure. Statistically significant changes in fold change gene expression relative to the vehicle control are denoted by $*$, where $* p \leq 0.05$,

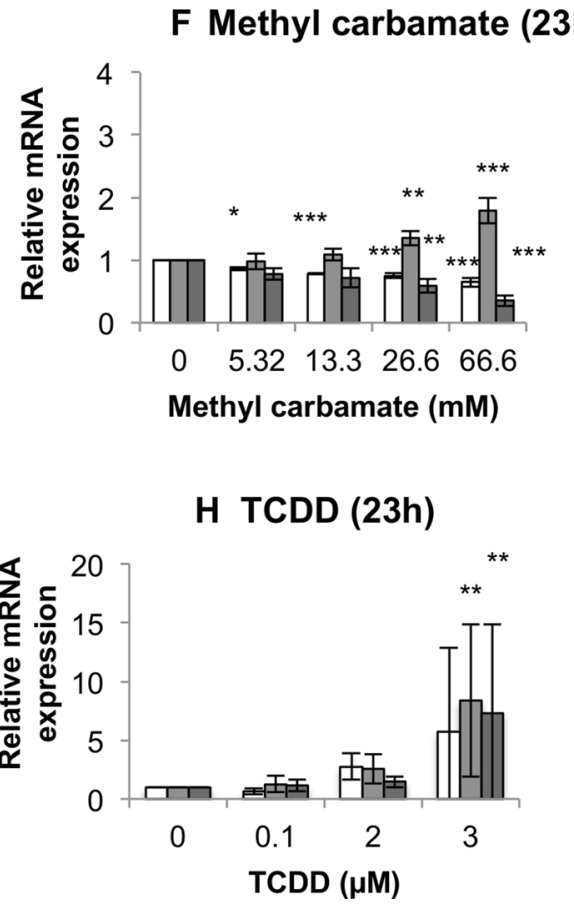

$* * p \leq 0.01$ and $* * * p \leq 0.001$. Arrows above selected concentrations correspond to the MN LOEL, or concentration nearest to the LOEL, for carcinogens, where applicable 

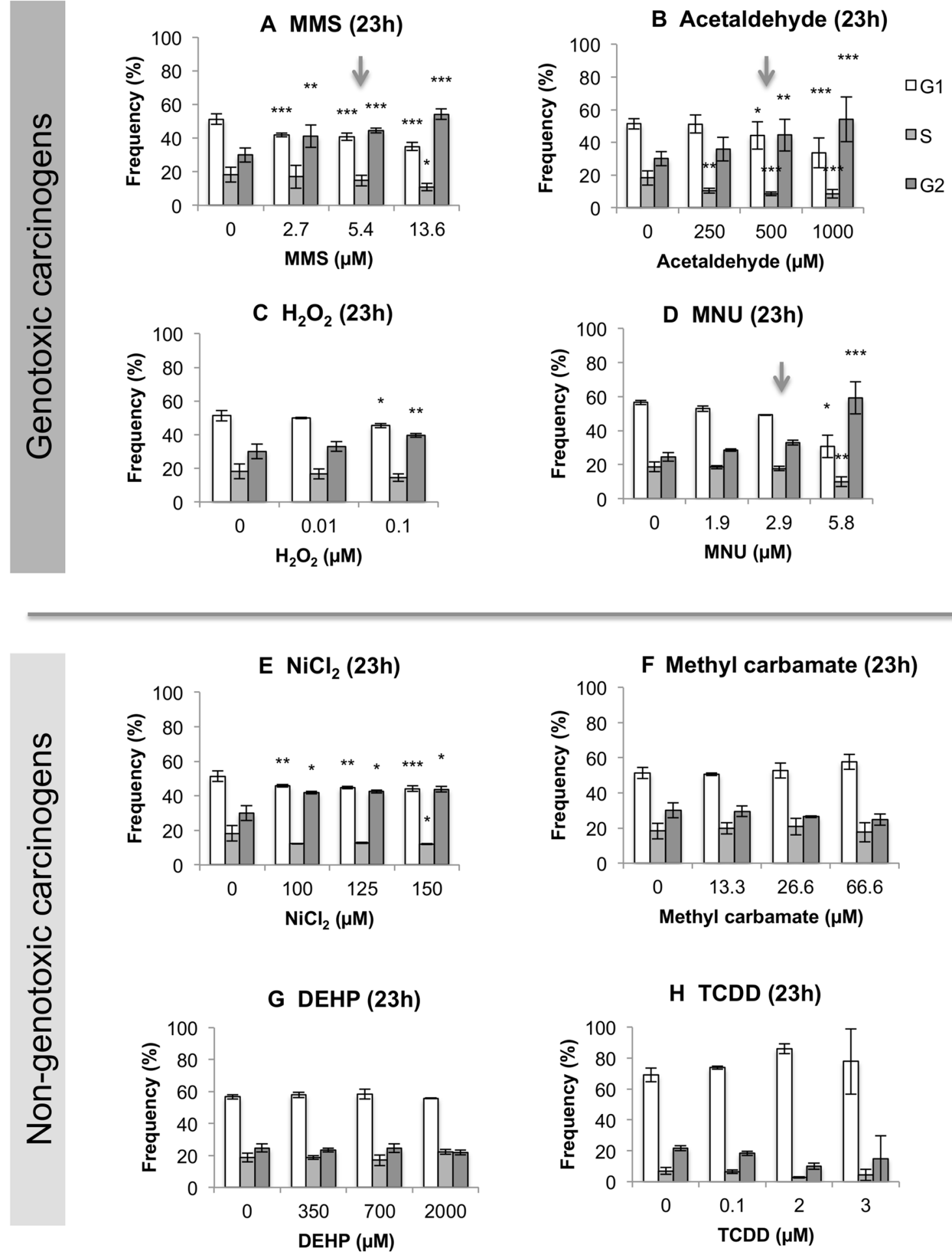

Fig. 4 Cell cycle analysis was performed using flow cytometry for samples treated for $23 \mathrm{~h}(n=3)$. A historical vehicle (either $\mathrm{H}_{2} \mathrm{O}$ or DMSO) control was used for all chemicals. Statistically significant changes in percentage cells relative to the vehicle control are denoted

by $*$, where $* p \leq 0.05,{ }^{* *} p \leq 0.01$ and $* * * p \leq 0.001$. Arrows above selected concentrations correspond to the MN LOEL for carcinogens, where applicable 
distribution at $4 \mathrm{~h}$ (data not shown); therefore, a $23 \mathrm{~h}$ exposure with lower $\mathrm{H}_{2} \mathrm{O}_{2}$ concentrations was completed (Fig. 4a). Lower concentrations were used for $23 \mathrm{~h}$ than $4 \mathrm{~h}$, to prevent reductions in RPD exceeding 50\%. Similarly to three of the GCs, the $\mathrm{NGC} \mathrm{NiCl}_{2}$ (Fig. 4e) caused G2 cellcycle arrest, with this being observed at all tested concentrations (i.e., $\geq 100 \mu \mathrm{M}$ ). No significant alterations in cell-cycle were observed for the remaining NGCs (Fig. $4 \mathrm{f}-\mathrm{h}$ ).

\section{The majority of chemicals caused cell and nuclear morphological changes}

Cell morphological changes have previously been associated with metastasis and invasion (Grünert et al. 2003; Tsai and Yang 2013) and are the basis of CTAs. Metastasis is closely associated with cancer mortality in humans and invasion links to the epithelial to mesenchymal transition (EMT). Therefore, cell morphology may provide a powerful early indicator of carcinogenesis-associated alterations.

Three out of four GCs significantly altered cell area (Fig. 5) relative to the vehicle control. The NGCs generally gave a greater response for cell area than for nuclear area, which contrasted with some of the GC data. With the exception of TCDD, the NGCs caused a significant reduction in cell area, each significantly increasing the "Lowest"/"Smallest" cell category (Fig. 5e-g). The greatest cell area decrease was observed with $\mathrm{NiCl}_{2}$, which caused the percentage of cells $<137 \mu \mathrm{m}^{2}$ to decrease by 23\% (Fig. 5e). TCDD (Figs. 5, 6h) was the only chemical that did not alter cell or nuclear area.

For nuclear area, a greater level of significance was generally observed for the GCs than for cell area (Figs. 5, 6, Supplementary File 5). For example, MNU produced a highly significant $(p<0.0002)$ increase in nuclei of $>90.1 \mu \mathrm{m}^{2}$ from 19 to $38 \% . \mathrm{H}_{2} \mathrm{O}_{2}$ caused the "Smallest" range of the nuclei (Fig. 6a) $\left(<95 \mu \mathrm{m}^{2}\right)$ to increase more than threefold, from 20 to $64 \%$. In addition, acetaldehyde did not have any significant effect on cell area whilst a significant, 5\% decrease of "Small" sized nuclei was observed. The extent of statistical significance for the two morphology endpoints is summarised in Fig. 6.

\section{Bioenergetics analysis revealed trends for carcinogens}

Mitochondrial and glycolytic flux were measured using the Seahorse $\mathrm{XF}^{\mathrm{e}} 24$ Analyzer (Fig. 7) to determine whether carcinogens influenced cellular bioenergetic profiles. Figure 7 models the shift from vehicle controls towards "stressed" phenotypes following chemical treatment (Robinson et al. 2012). Although no changes were significant, general trends were apparent. MNU, MC and acetaldehyde induced a shift towards an "energetic" phenotype. $\mathrm{NiCl}_{2}$, DEHP and MMS shifted cells towards quiescence, reducing both OCR and ECAR. $\mathrm{NiCl}_{2}$ reduced OCR by almost threefold at $150 \mu \mathrm{M}$, from $459 \mathrm{pmol} / \mathrm{min}$ to $156.8 \mathrm{pmol} / \mathrm{min}$, while simultaneously reducing ECAR by 1.8 -fold. Interestingly, $\mathrm{NiCl}_{2}$ also elevated ROS concentrations, as mentioned previously (Supplementary File 5). $\mathrm{H}_{2} \mathrm{O}_{2}$ caused a more glycolytic phenotype, whereas TCDD demonstrated contrasting trends at different concentrations.

\section{Endpoints were summarized using the ToxPi GUI}

To visualise trends for different endpoints and to rank the chemicals in terms of their toxicological impact, ToxPi GUI was used to generate a diagrammatical representation for each chemical (Fig. 8). Composite scores for all endpoints were generated for each chemical, in an attempt to predict their rank order in terms of carcinogenic effects.

In terms of the ToxPi profiles, the GCs produced broadly similar distributions, altering similar endpoints, in particular p53, phospho-p53, cell-cycle distribution, cell and nuclear area, and MN frequency. Within the five highest-ranking scores, four of these were GCs, with scores ranging from 60.2 for $\mathrm{MNU}$ to 36.5 for acetaldehyde. Meanwhile, $\mathrm{H}_{2} \mathrm{O}_{2}$ produced a score of 52.7 and MMS, 40.7. It is important to note that $\mathrm{H}_{2} \mathrm{O}_{2}$ was the only chemical where endpoints were measured at $4 \mathrm{~h}$, rendering it the most potent compound overall despite not achieving the greatest score.

NGCs generally produced the lowest scores, with three ranking 6th-8th, as follows: $\mathrm{MC}$ (29.2), $\mathrm{NiCl}_{2}$ (27.1) and DEHP (26.4). This complemented the fact that NGCs altered fewer carcinogenicity endpoints than GCs. The ToxPi profiles displayed noticeable similarities between these three chemicals, despite p21, p53 and cell-cycle arrest being induced by $\mathrm{NiCl}_{2}$ only. TCDD, however, elicited a greater effect than other NGCs, producing the third highest score (42.3). This high rank was almost entirely due to the large gene expression increases induced by TCDD, as this chemical did not alter any other endpoints. As a result, TCDD's ToxPi profile indicates a somewhat unique response compared to other chemicals, differing from that of either carcinogen group.

Furthermore, the ToxPi profiles and accompanying rank order demonstrated potential for read-across between carcinogen classes, indicating some separation between GCs and NGCs, with GCs generally inducing greater responses for these endpoints. 
Fig. 5 Violin plots displaying cell area changes within data obtained via the INCell Analyzer, followed by Matlab-based image analysis. The frequency of cells (\%) in each quintile category is plotted. The cell area ranges represented by the quintiles are included in Supplementary File 2. Alterations of the percentage of cells/nuclei within these set ranges were compared following treatment with carcinogens. Statistically significant changes in percentage cells relative to the vehicle control are denoted by $*$, where $* p \leq 0.05, * * p \leq 0.01$ and $* * * p \leq 0.001$. These are summarised in Supplementary File 3. No recovery time (i.e., $0 \mathrm{~h}$ ) was allowed following the treatment period, due to data collection at 8 and $23 \mathrm{~h}$ recoveries consistently demonstrating reduced effects on morphology compared to $0 \mathrm{~h}$. Other morphology endpoints, such as cell and nuclear perimeter, solidity and form factor were also determined using the script-based analysis method, increasing confidence in the cell and nuclear area changes observed (colour figure online)
A MMS (23h) Cell Area

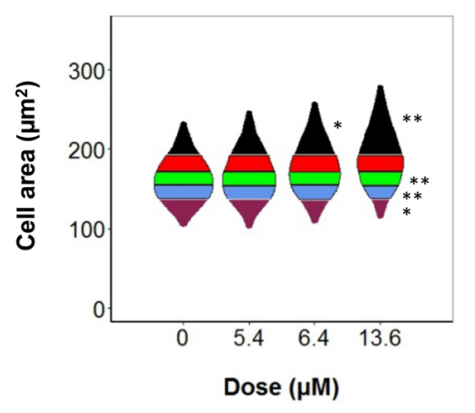

C $\mathrm{H}_{2} \mathrm{O}_{2}(4 \mathrm{~h})$ Cell Area

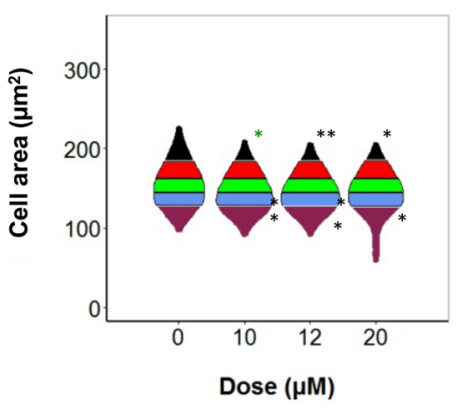

E NiCl2 (23h) Cell Area

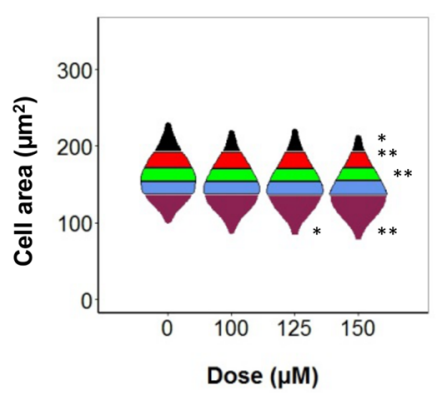

G DEHP (23h) Cell Area

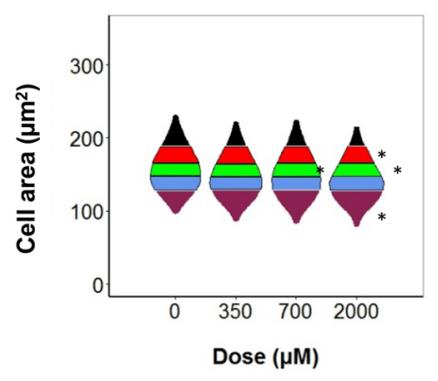

B Acetaldehyde (23h) Cell Area

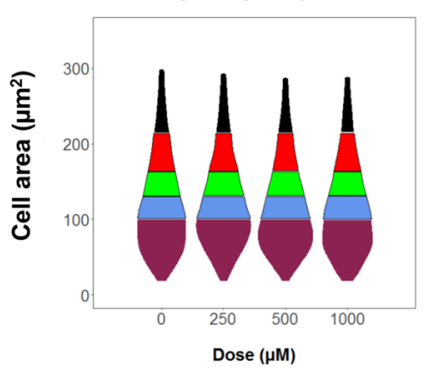

D MNU (23h) Cell Area

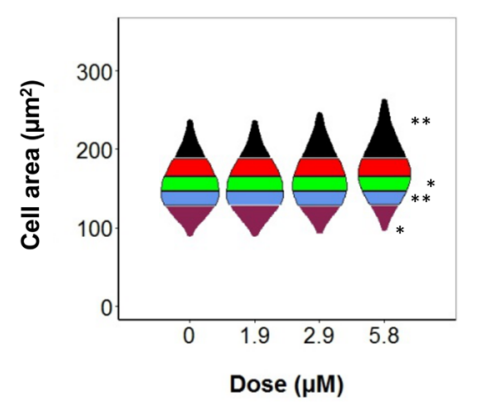

F Methyl Carbamate (23h) Cell Area

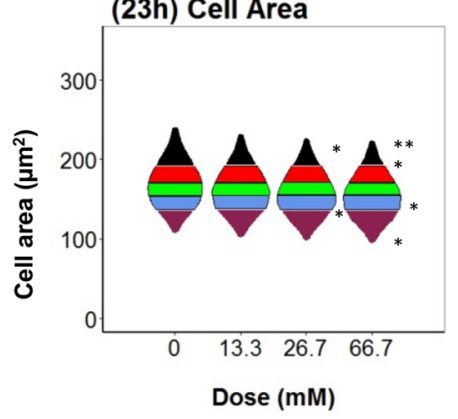

H TCDD (23h) Cell Area

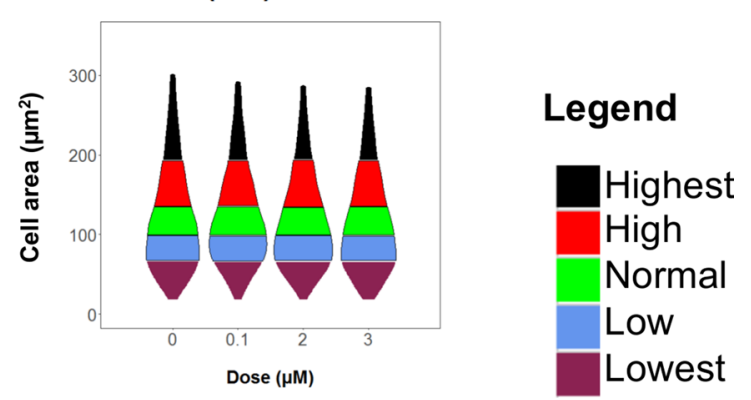

\section{Discussion}

The accurate prediction of a novel chemical's carcinogenic potential in humans is crucial if cancer prevention is to be a possibility. Analysis of phenotypic changes of human cells in response to carcinogens is essential for fully understanding human oncogenesis. Holistic testing of carcinogens offers many advantages over the testing of isolated endpoints
(Benigni 2014; Bourcier et al. 2015; Breheny et al. 2011; McKim and James 2010), ranging from improved predictivity to reduced time and financial costs (Kirsch-Volders et al. 1997; Stankowski et al. 2015). The use of in vitro testing approaches and chemical mode-of-action identification is currently favoured (Adeleye et al. 2015; EPA 2005; Thybaud et al. 2007). Indeed, many mechanism-centric in vitro tests using "next generation" approaches for identifying 


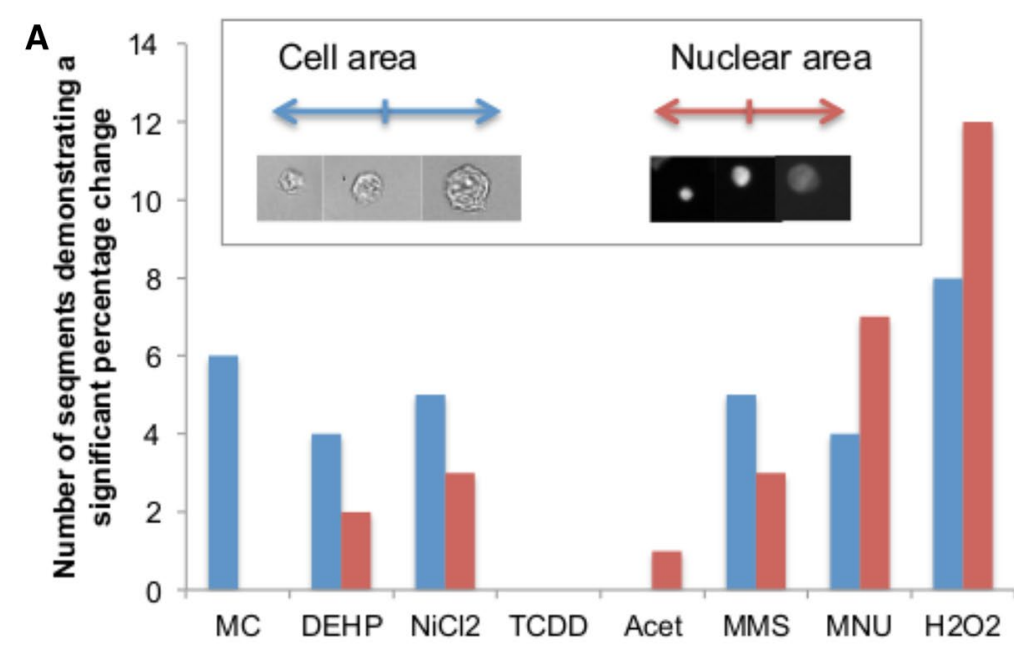

Non-genotoxic carcinogens Genotoxic carcinogens

$=$ Cell area $=$ Nuclear area

B $\quad 0$ control
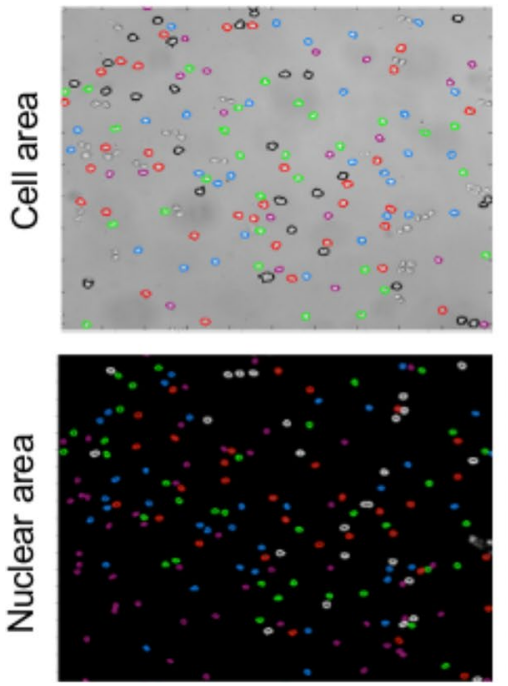

13.6 $\mu \mathrm{M}$ MMS
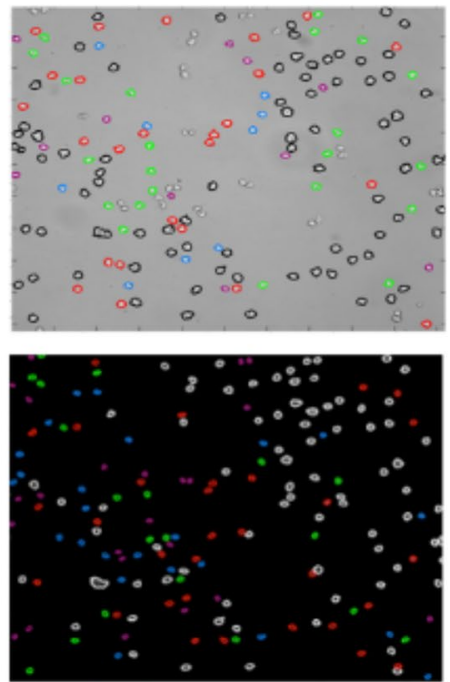

\section{Cell Area Range $\left(\mu \mathrm{M}^{2}\right)$}

\begin{tabular}{ll}
\hline Highest & $192.62 \leq$ \\
\hline $\begin{array}{l}\text { High } \\
\text { Normal }\end{array}$ & $171.54-192.62$ \\
\hline Low & $154.83-171.54$ \\
\hline Lowest & $137.17-154.83$ \\
\hline & $0-137.17$
\end{tabular}

Nuclear Area Range $\left(\mu \mathrm{M}^{2}\right)$

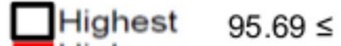

High $\quad 83.51-95.69$

Normal $\quad 73.93-83.51$

Low

Lowest

$$
0-64.07
$$

Fig. 6 a Graphical summary of the total number of quintiles producing statistically significant changes relative to the untreated control for the two different morphological endpoints: cell area (Fig. 5) and nuclear area (Supplementary File 5). Inset: Example images of randomly selected "small", "medium" and "large" cell and nuclear

carcinogens have been developed (Caiment et al. 2013; Gusenleitner et al. 2014; Herwig et al. 2016; Tilton et al. 2015), with these linking to cancer hallmarks or toxicity prioritisation (Dix et al. 2007; Kleinstreuer et al. 2012; Smith et al. 2016).

This study's objective was to further develop such approaches, determining whether the carcinogenic images captured using the INCell Analyzer 2000. b Colour-coded cell and nuclear perimeters overlaid on randomly selected raw images obtained via the INCell Analyzer, to illustrate an increase in cell (black outlines) and nuclear (white outlines) area $\left(\mu \mathrm{m}^{2}\right)$ following 13.6 $\mu \mathrm{M}$ MMS treatment (colour figure online)

potential of known in vivo carcinogens could be successfully identified via an in vitro, multi-endpoint test system, with particular interest in identifying NGCs. Ten molecular and cellular "surrogate" carcinogenicity endpoints reflecting the "Hallmarks of Cancer" (Hanahan and Weinberg 2011) were selected to test eight carcinogens. 
Fig. 7 Bioenergetics analysis of control and treated cells using the Seahorse $\mathrm{XF}^{\mathrm{e}} 24$ Bioanalyzer $(n \geq 3)$ to establish whether chemicals induced a "stressed" phenotype. OCR is plotted against ECAR for basal cellular metabolic rates. Historical vehicle controls $\left(\mathrm{H}_{2} \mathrm{O}, \mathrm{DMSO}\right)$ are included and blue points correspond to $\mathrm{H}_{2} \mathrm{O}$ chemicals, whereas red points correspond to DMSO chemicals. Green points correspond to TCDD, which was analysed in a different cell line (MCL-5). Cluster analysis was performed on the data. Four bioenergetic states were included [Quiescent, aerobic (oxidative phosphorylation), glycolytic and energetic (glycolytic + oxidative phosphorylation)] that represent the energy phenotype (colour figure online)

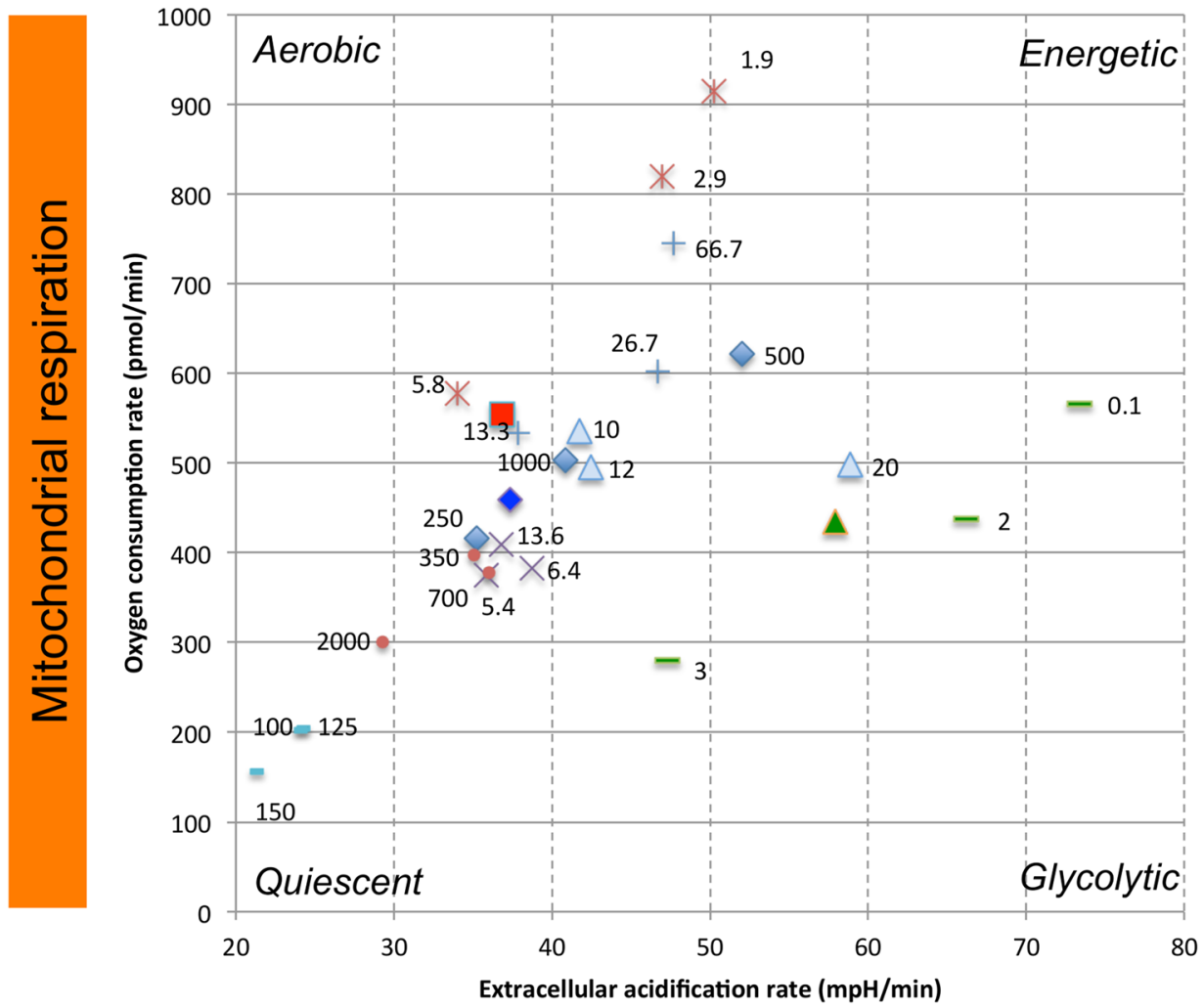

Glycolysis

$\begin{array}{ll}\diamond \text { Acetaldehyde } & \triangle \mathrm{H} 2 \mathrm{O} 2 \\ -\mathrm{DEHP} & +\mathrm{MC} \\ \bullet \mathrm{H} 2 \mathrm{O} & \text { 口DMSO }\end{array}$

* MNU

$-T C D D$

$\triangle \mathrm{MCL} 5$

\section{Multi-endpoint analysis provided more informative risk assessment}

A flow diagram was created to summarise the relationships between the endpoints, or "adverse outcomes" (Supplementary File 6), based on the data. Generally, similar trends for the GCs were apparent for p53, p21 and the cell-cycle, reflecting the outcomes of studies such as (Lukas et al. 2004). Cell morphology, however, indicated some diversity in trends for GCs: MMS and MNU increased cell and nuclear area, in agreement with relative cellular size at G2 phase (Figs. 5, 6). In contrast, $\mathrm{H}_{2} \mathrm{O}_{2}$ markedly reduced cell and nuclear area (Figs. 5,6), possibly linking to its shorter exposure duration $(4 \mathrm{~h})$. However, this also reflects some NGC trends, perhaps suggesting a ROS-centric mechanism (Stannard et al. 2016). It was hypothesised that the mammalian target of rapamycin (mTOR) may orchestrate cell morphology alterations (Fumarola et al. 2005; Llanos et al. 2016; Pincus and Theriot 2007). Indeed, we have noted that mTOR-inhibitor rapamycin reduced cell and nuclear area, indicating effects similar to some test carcinogens (Supplementary File 7). In general, NGCs induced fewer significant effects than GCs, with these mainly involving gene expression and cell morphology alterations (Figs. 3, 5, 6, Supplementary File 6). No significant effects were observed for bioenergetics, which may be unsurprising when using low-doses; however, this endpoint remains valuable for carcinogenicity testing. The use of holistic endpoints could be considered synonymous with "key events" of the Adverse Outcome Pathway (AOP) concept. However, the present approach avoids the limitations of focusing on a single pathway, as a combination of both molecular- and cellular-level changes are considered.

Data for the multiple endpoints could, with further optimisation, be multiplexed within a single, high-content system, such as the INCell Analyzer. For example, MN and cell-cycle data can already be collected simultaneously via this approach. Furthermore, while endpoints were selected based on their relationship to the "Hallmarks of Cancer", one of the major original hallmarks, resistance 


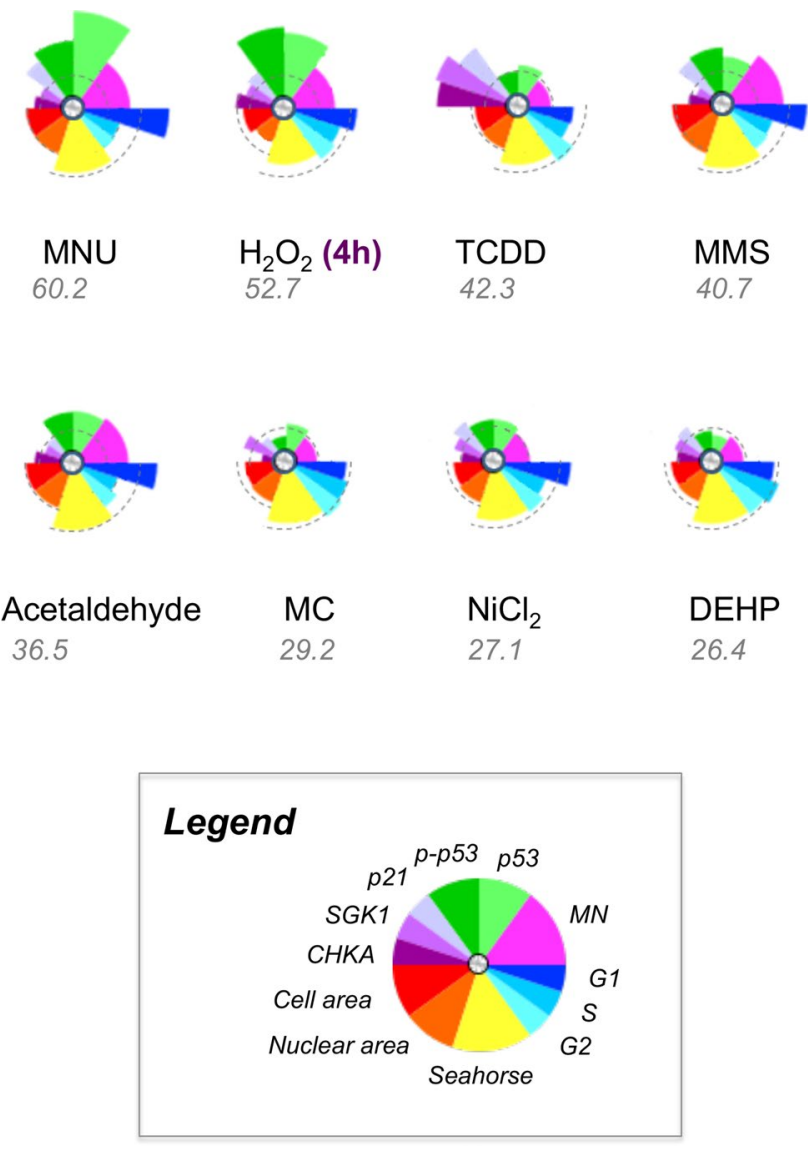

Fig. 8 Outputs from the Toxicological Prioritization Index (ToxPi) GUI summarising the fold changes for the endpoints at the 50\% RPDinducing concentration. Broken lines indicate the position of "onefold" for the relevant endpoints. Carcinogens were ranked according to their potency scores, from highest to lowest. Fold changes were square rooted, transformed and weighted as appropriate (i.e., 3 for each of "MN" and "Seahorse", 1.5 for each of "cell area", "nuclear area", "p53" and "phospho-p53", and 1 for each of the remaining endpoints), and values < onefold were inverted to give values $>$ onefold (for down-regulation). The sum all values for all endpoints was taken for each chemical, generating a final overall score. Data were scaled to provide three separate groups of "onefold" magnitude, due to notable variation in the magnitude of changes for different endpoints and, therefore, to ensure clear visualisation of all endpoint "slices" (colour figure online)

to apoptosis, was not included. This is due to the low concentrations of chemical used inducing only minimal levels of apoptosis, meaning that resistance to apoptosis would be difficult to measure effectively.

Another important aspect of validation relates to "noncarcinogens", as it is necessary to ensure that such chemicals deliver negative results. Extensive validation of this class is beyond the scope of the present study. However, the vehicles used, $\mathrm{H}_{2} \mathrm{O}$ and DMSO, are non-carcinogens and did not adversely alter the endpoints tested. The lack of effect for these chemicals provided support for the assay's specificity.

\section{The CBMN assay exhibited limited sensitivity for detecting carcinogenic outcomes}

Importantly, for the GCs, alterations in other, non-MN endpoints (Figs. 3, 4) often occurred at concentrations lower than the LOEL for MN frequency. This suggests that other, non-genotoxicity endpoints offer greater sensitivity for GC detection than the CBMN assay. This may be due to the efficient removal of potentially clastogenic DNA lesions via DNA repair mechanisms at low doses; should such lesions remain unrepaired, these may also not necessarily cause the "late" cellular events that are MN (Fenech 1997). These protective factors reduce the frequency of observed clastogenic events (e.g., MN), and so the full DNA damage profile induced by the chemical may not be evident. The fact that the CBMN assay is not designed to detect NGCs further supports the use of multi-endpoint testing, particularly considering NGCs' diverse mechanisms.

Importantly, all chemicals caused at least one statistically significant change in the endpoints tested; this again supports the use of multiple endpoint tests, as these may reduce the probability of "missing" biological impacts of carcinogens. No chemicals exhibited adverse effects at all concentrations tested for all endpoints, with low concentrations, unsurprisingly, being less likely to induce an effect.

\section{Discrete categories of carcinogens may be irrelevant: $\mathrm{NiCl}_{2}$ exhibited GC-like effects}

While this study has provided mechanistic insights for individual carcinogens (Supplementary File 6), the overall, integrated results for chemicals were also informative. The resulting scores (Fig. 8), when ranked from highest to lowest, indicated a general separation between GCs and NGCs, with four of the five highest scores belonging to GCs. However, despite GCs and NGCs potentially affecting different endpoints, the incomplete separation between these groups suggested that carcinogens should be analysed on a caseby-case basis. Therefore, this study proves that dividing carcinogens into discrete categories such as "genotoxic" and "non-genotoxic" may be an oversimplification, a case in point being $\mathrm{NiCl}_{2} . \mathrm{NiCl}_{2}$ conferred several effects that overlapped with those of GCs, such as p53 activation and G2 cell-cycle arrest, despite not being observed to induce genotoxicity in this study (Fig. 1) or in some other studies (Biggart and Costa 1986; Chakrabarti et al. 2001). Therefore, $\mathrm{NiCl}_{2}$ may not be a true NGC, as was previously believed, and its genotoxicity may be dependent on its exposure time (Stannard et al. 2016). It is, therefore, apparent that different groups of carcinogens have a unique in vitro "fingerprint" or "signature" for carcinogenicity. This could be termed the "Integrated Signature of Carcinogenicity" (ISC), representing the overall, multiple-endpoint response of cells in vitro 
to any test chemical (Fig. 8). With further validation, it is possible that a "cut-off" ISC value could be identified, enabling GCs to be distinguished from NGCs.

\section{In vitro and in vivo rankings were broadly aligned}

Relating rank order, or ISCs, to in vivo carcinogenicity data may be informative, particularly as such an approach may replace the two-year rodent carcinogenicity bioassay for non-pharmaceuticals, impacting on the chemical industry. $\mathrm{TD}_{50}$ data for the chemicals (Gold database) are listed below:

TCDD: $0.000023 \mathrm{mg} / \mathrm{kg} / \mathrm{day}$; rat

MNU: $0.0927 \mathrm{mg} / \mathrm{kg} /$ day; rat

MMS: $32 \mathrm{mg} / \mathrm{kg} /$ day; mouse

MC: $56 \mathrm{mg} / \mathrm{kg} / \mathrm{day}$; rat

Acetaldehyde: $153 \mathrm{mg} / \mathrm{kg} / \mathrm{day}$; rat

DEHP: $716 \mathrm{mg} / \mathrm{kg} /$ day; rat

$\mathrm{H}_{2} \mathrm{O}_{2}: 7,540 \mathrm{mg} / \mathrm{kg} /$ day; mouse

$\mathrm{NiCl}_{2}$ : Data unavailable

The in vitro and in vivo data indicated broad agreement: three of the four most potent in vivo carcinogens, based on these chemicals' $\mathrm{TD}_{50}$ doses, corresponded with the ToxPi rankings for the 50\% RPD concentrations, despite a slightly different ranking order; however, $\mathrm{H}_{2} \mathrm{O}_{2}$ appears to be considerably less potent in vivo, being ranked last. Interestingly, $\mathrm{H}_{2} \mathrm{O}_{2}$ was the most potent chemical in vitro, being the only chemical to induce genotoxicity after $4 \mathrm{~h}$ while producing the second highest ToxPi score. This difference could be explained by the greater antioxidant capacity in vivo (Niki 2010) compared to in vitro systems, which are known to be hyperoxic and devoid of protective antioxidants. Another explanation may relate to the in vivo method of exposure being via the animals' water, contributing to losses of unstable $\mathrm{H}_{2} \mathrm{O}_{2}$ to, for example, digestive system microbiota. The highestranking in vivo carcinogen was TCDD, whereas in vitro, GCs ranked higher.

\section{Conclusions}

The present study has established that a multiple-endpoint approach is a more comprehensive means of assessing carcinogenicity of environmental carcinogens in vitro than traditional, single-endpoint tests. Crucially, this novel testing strategy will provide a means of in vitro NGC detection. Advantages of our approach include use of low-doses, automated technology and genetically stable human cells. Such a test could eventually provide sufficient information to replace the two-year rodent carcinogenicity assay for non-pharmaceuticals, reducing animal use in carcinogenicity assessment. Further data for other chemicals and cell models, such as liver, are now required to verify these observations.

Acknowledgements A Strategic Award from the National Centre for the Replacement, Refinement and Reduction (3Rs) of Animals in Research (NC3Rs) (Reference NC/K500033/1) funded the research. Funding was also received from AstraZeneca and the BBSRC (Reference BB/L502546/1) and the UK Environmental Mutagen Society. The authors thank Margaret Clatworthy, Sally James (Swansea University), Dr Val Millar and Angela Davies (GE Healthcare) for technical assistance. The authors thank Professor David Kirkland for advising on compound selection and are grateful to Dr Timothy Stone for performing the RNA Microarray bioinformatics analysis.

\section{Compliance with ethical standards}

Conflict of interest The authors declare no conflict of interest.

Open Access This article is distributed under the terms of the Creative Commons Attribution 4.0 International License (http://creativecommons.org/licenses/by/4.0/), which permits unrestricted use, distribution, and reproduction in any medium, provided you give appropriate credit to the original author(s) and the source, provide a link to the Creative Commons license, and indicate if changes were made.

\section{References}

Adeleye Y, Andersen M, Clewell R et al (2015) Implementing toxicity testing in the 21 st Century (TT21C): making safety decisions using toxicity pathways, and progress in a prototype risk assessment. Toxicology 332:102-111

Avancini D, Menzies GE, Morgan C et al (2016) MutAIT: an online genetic toxicology data portal and analysis tools. Mutagenesis 31(3):323-328

Banin S, Moyal L, Shieh S-Y et al (1998) Enhanced phosphorylation of $\mathrm{p} 53$ by ATM in response to DNA damage. Science 281(5383):1674-1677

Bartsch H, Malaveille C (1989) Prevalence of genotoxic chemicals among animal and human carcinogens evaluated in the IARC Monograph series. Cell Biol Toxicol 5(2):115-127

Benigni R (2014) Predicting the carcinogenicity of chemicals with alternative approaches: recent advances. Expert Opin Drug Metab Toxicol 10(9):1199-1208

Beranek DT (1990) Distribution of methyl and ethyl adducts following alkylation with monofunctional alkylating agents. Mutat Res 231(1):11-30

Biggart NW, Costa M (1986) Assessment of the uptake and mutagenicity of nickel chloride in salmonella tester strains. Mutat Res Lett 175(4):209-215

Bock KW, Köhle C (2005) Ah receptor-and TCDD-mediated liver tumor promotion: clonal selection and expansion of cells evading growth arrest and apoptosis. Biochem Pharmacol 69(10):1403-1408

Bourcier T, McGovern T, Stavitskaya L, Kruhlak N, Jacobson-Kram D (2015) Improving prediction of carcinogenicity to reduce, refine, and replace the use of experimental animals. J Am Assoc Lab Anim Sci 54(2):163-169

Breheny D, Oke O, Faux SP (2011) The use of in vitro systems to assess cancer mechanisms and the carcinogenic potential of chemicals. Altern Lab Anim 39(3):233 
Brooks PJ, Theruvathu JA (2005) DNA adducts from acetaldehyde: implications for alcohol-related carcinogenesis. Alcohol 35(3):187-193

Brusehafer K, Rees BJ, Manshian BB et al (2014) Chromosome breakage induced by the genotoxic agents mitomycin $\mathrm{C}$ and cytosine arabinoside is concentration and p53 dependent. Toxicol Sci 140(1):94-102. https://doi.org/10.1093/toxsci/kfu058

Caiment F, Tsamou M, Jennen D, Kleinjans J (2013) Assessing compound carcinogenicity in vitro using connectivity mapping. Carcinogenesis 35(1):201-207

Caldwell JC (2012) DEHP: genotoxicity and potential carcinogenic mechanisms-a review. Mutat Res 751(2):82-157

Casals-Casas C, Desvergne B (2011) Endocrine disruptors: from endocrine to metabolic disruption. Annu Rev Physiol 73:135-162

Chakrabarti SK, Bai C, Subramanian KS (2001) DNA-protein crosslinks induced by nickel compounds in isolated rat lymphocytes: role of reactive oxygen species and specific amino acids. Toxicol Appl Pharmacol 170(3):153-165

Chan PC, Huff J, Haseman JK, Quest JA, Hall W (1992) Liver carcinogenesis by methyl carbamate in $\mathrm{F} 344$ rats and not in $\mathrm{B} 6 \mathrm{C} 3 \mathrm{~F} 1$ mice. Jpn J Cancer Res 83(3):258-263

Council NR (2007) Toxicity testing in the 21 st century: a vision and a strategy. National Academies Press, Washington, D.C.

de Molina AR, Rodríguez-González AN, Gutiérrez R et al (2002) Overexpression of choline kinase is a frequent feature in human tumor-derived cell lines and in lung, prostate, and colorectal human cancers. Biochem Biophys Res Commun 296(3):580-583

Dix DJ, Houck KA, Martin MT, Richard AM, Setzer RW, Kavlock RJ (2007) The ToxCast program for prioritizing toxicity testing of environmental chemicals. Toxicol Sci 95(1):5-12

Doak SH, Jenkins GJ, Johnson GE, Quick E, Parry EM, Parry JM (2007) Mechanistic influences for mutation induction curves after exposure to DNA-reactive carcinogens. Cancer Res 67(8):3904-3911

EPA (2005) Guidelines for Carcinogen Risk Assessment, US EPA

Fenech M (1997) The advantages and disadvantages of the cytokinesisblock micronucleus method. Mutat Res 392(1):11-18

Finnegan M, Linley E, Denyer SP, McDonnell G, Simons C, Maillard J-Y (2010) Mode of action of hydrogen peroxide and other oxidizing agents: differences between liquid and gas forms. J Antimicrob Chemother 65(10):2108-2115. https://doi.org/10.1093/jac/dkq308

Fumarola C, La Monica S, Alfieri RR, Borra E, Guidotti GG (2005) Cell size reduction induced by inhibition of the mTOR/S6 K-signaling pathway protects Jurkat cells from apoptosis. Cell Death Differ 12(10):1344-1357. https://doi.org/10.1038/sj.cdd.4401660

Grünert S, Jechlinger M, Beug H (2003) Diverse cellular and molecular mechanisms contribute to epithelial plasticity and metastasis. Nat Rev Mol Cell Biol 4(8):657-665

Gusenleitner D, Auerbach SS, Melia T, Gómez HF, Sherr DH, Monti S (2014) Genomic models of short-term exposure accurately predict long-term chemical carcinogenicity and identify putative mechanisms of action. PLoS One 9(7):e102579

Guyton KZ, Kyle AD, Aubrecht J et al (2009) Improving prediction of chemical carcinogenicity by considering multiple mechanisms and applying toxicogenomic approaches. Mutat Res 681(2-3):230 240. https://doi.org/10.1016/j.mrrev.2008.10.001

Hanahan D, Weinberg RA (2000) The hallmarks of cancer. Cell 100(1):57-70

Hanahan D, Weinberg RA (2011) Hallmarks of cancer: the next generation. Cell 144(5):646-674

Hernandez LG, van Steeg H, Luijten M, van Benthem J (2009) Mechanisms of non-genotoxic carcinogens and importance of a weight of evidence approach. Mutat Res 682(2-3):94-109. https://doi. org/10.1016/j.mrrev.2009.07.002
Herwig R, Gmuender H, Corvi R et al (2016) Inter-laboratory study of human in vitro toxicogenomics-based tests as alternative methods for evaluating chemical carcinogenicity: a bioinformatics perspective. Arch Toxicol 90(9):2215-2229

HSDB (2000) Hazardous Substances Database. National Library of Medicine. https://toxnet.nlm.nih.gov/cgi-bin/sis/search2/f?./ temp/ fCbYgL:1. Accessed 2 Nov 2017

Hukkanen J, Lassila A, Paivarinta K et al (2000) Induction and regulation of xenobiotic-metabolizing cytochrome P450 s in the human A549 lung adenocarcinoma cell line. Am J Respir Cell Mol Biol 22(3):360-366

Ioannou Y, Sanders J, Matthews H (1988) Methyl carbamate. Speciesdependent variations in metabolism and clearance in rats and mice. Drug Metab Disposition 16(3):435-440

Joseph BA, Stephen EM (1971) Modified methylolated aliphatic carbamate permanent press textile resin. Google Patents

Ke Q, Davidson T, Chen H, Kluz T, Costa M (2006) Alterations of histone modifications and transgene silencing by nickel chloride. Carcinogenesis 27(7):1481-1488

Kerckaert GA, Isfort RJ, Carr GJ, Aardema MJ, LeBoeuf RA (1996) A comprehensive protocol for conducting the Syrian hamster embryo cell transformation assay at $\mathrm{pH}$ 6.70. Mutat Res 356(1):65-84

Kim JY, Kwon J, Kim JE et al (2005) Identification of potential biomarkers of genotoxicity and carcinogenicity in L5178Y mouse lymphoma cells by cDNA microarray analysis. Environ Mol Mutagen 45(1):80-89

Kim K-H, Kabir E, Jahan SA (2016) The use of personal hair dye and its implications for human health. Environ Int 89:222-227

Kirkland D, Aardema M, Henderson L, Muller L (2005) Evaluation of the ability of a battery of three in vitro genotoxicity tests to discriminate rodent carcinogens and non-carcinogens I. Sensitivity, specificity and relative predictivity. Mutat Res 584(1-2):1-256. https://doi.org/10.1016/j.mrgentox.2005.02.004

Kirkland D, Kasper P, Martus H-J et al (2016) Updated recommended lists of genotoxic and non-genotoxic chemicals for assessment of the performance of new or improved genotoxicity tests. Mutat Res 795:7-30

Kirsch-Volders M, Elhajouji A, Cundari E, Van Hummelen P (1997) The in vitro micronucleus test: a multi-endpoint assay to detect simultaneously mitotic delay, apoptosis, chromosome breakage, chromosome loss and non-disjunction. Mutat Res 392(1):19-30

Kleinstreuer NC, Dix DJ, Houck KA et al (2012) In vitro perturbations of targets in cancer hallmark processes predict rodent chemical carcinogenesis. Toxicol Sci 131(1):40-55

Knerr S, Schrenk D (2006) Carcinogenicity of 2,3,7,8-tetrachlorodibenzo- $p$-dioxin in experimental models. Mol Nutr Food Res 50(10):897-907. https://doi.org/10.1002/mnfr.200600006

Kruger T, Long M, Bonefeld-Jorgensen EC (2008) Plastic components affect the activation of the aryl hydrocarbon and the androgen receptor. Toxicology 246(2-3):112-123. https://doi.org/10.1016/j. tox.2007.12.028

Kwon K-J, Go S-Y, Park S-N, Sheen Y-Y (2007) Genetic toxicity test of methylcarbamate by Ames, micronucleus, Comet assays and microarray analysis. Biomol Ther 15(3):199-204

Lang F, Perrotti N, Stournaras C (2010) Colorectal carcinoma cellsregulation of survival and growth by SGK1. Int J Biochem Cell Biol 42(10):1571-1575

Lijinsky W (1992) Chemistry and biology of $N$-nitroso compounds. Cambridge University Press, Cambride

Llanos S, Garcia-Pedrero JM, Morgado-Palacin L, Rodrigo JP, Serrano M (2016) Stabilization of $\mathrm{p} 21$ by mTORC1/4E-BP1 predicts clinical outcome of head and neck cancers. Nat Commun. https://doi. org/10.1038/ncomms 10438 
Long ME (2007) Predicting carcinogenicity in humans: the need to supplement animal-based toxicology. AATEX 14:553-559

Lukas J, Lukas C, Bartek J (2004) Mammalian cell cycle checkpoints: signalling pathways and their organization in space and time. DNA Repair (Amst) 3(8-9):997-1007. https://doi.org/10.1016/j. dnarep.2004.03.006

Mandal PK (2005) Dioxin: a review of its environmental effects and its aryl hydrocarbon receptor biology. J Comp Physiol [B] 175(4):221-230. https://doi.org/10.1007/s00360-005-0483-3

McKim J, James M (2010) Building a tiered approach to in vitro predictive toxicity screening: a focus on assays with in vivo relevance. Comb Chem High Throughput Screen 13(2):188-206

Melnick RL, Kohn MC, Portier CJ (1996) Implications for risk assessment of suggested nongenotoxic mechanisms of chemical carcinogenesis. Environ Health Perspect 104(Suppl 1):123-134

Mitchell A, Auletta A, Clive D, Kirby P, Moore M, Myhr B (1997) The L5178Y/tk \pm mouse lymphoma specific gene and chromosomal mutation assay: A phase III report of the US environmental protection agency Gene-Tox program1This manuscript has been reviewed by the US Environmental Protection Agency Office of Toxic Substances, Pollution Prevention and Toxics, and the US Environmental Protection Agency National Health and Environmental Effects Research Laboratory and approved for publication. Approval does not signify that the contents necessarily reflect the views and policies of the Agency, nor does mention of trade names or commercial products constitute endorsement or recommendation for use. 1. Mutat Res 394(1):177-303

Muller L, Kikuchi Y, Probst G et al (1999) ICH-harmonised guidances on genotoxicity testing of pharmaceuticals: evolution, reasoning and impact. Mutat Res 436(3):195-225

Niki E (2010) Assessment of antioxidant capacity in vitro and in vivo. Free Radic Biol Med 49(4):503-515

Pincus Z, Theriot JA (2007) Comparison of quantitative methods for cell-shape analysis. J Microsc 227(Pt 2):140-156. https://doi. org/10.1111/j.1365-2818.2007.01799.x

Pinkernell U, Effkemann S, Karst U (1997) Simultaneous HPLC determination of peroxyacetic acid and hydrogen peroxide. Anal Chem 69(17):3623-3627

Reif DM, Martin MT, Tan SW et al (2010) Endocrine profiling and prioritization of environmental chemicals using ToxCast data. Environ Health Perspect 118(12): 1714

Reif DM, Sypa M, Lock EF et al (2013) ToxPi GUI: an interactive visualization tool for transparent integration of data from diverse sources of evidence. Bioinformatics 29(3):402-403

Robinson G, Dinsdale D, Macfarlane M, Cain K (2012) Switching from aerobic glycolysis to oxidative phosphorylation modulates the sensitivity of mantle cell lymphoma cells to TRAIL. Oncogene 31(48):4996-5006

Rusyn I, Peters JM, Cunningham ML (2006) Modes of action and species-specific effects of di-(2-ethylhexyl)phthalate in the liver. Crit Rev Toxicol 36(5):459-479. https://doi. org/10.1080/10408440600779065

Sampson J, de Korte D (2011) DEHP-plasticised PVC: relevance to blood services*. Transfus Med 21(2):73-83. https://doi. org/10.1111/j.1365-3148.2010.01056.x

Seager AL, Shah UK, Brusehafer K et al (2014) Recommendations, evaluation and validation of a semi-automated, fluorescentbased scoring protocol for micronucleus testing in human cells. Mutagenesis 29(3):155-164. https://doi.org/10.1093/mutage/ geu008

Smith MT, Guyton KZ, Gibbons CF et al (2016) Key characteristics of carcinogens as a basis for organizing data on mechanisms of carcinogenesis. Environ Health Perspect (Online) 124(6):713

Stankowski LF, Aardema MJ, Lawlor TE et al (2015) Integration of Pig-a, micronucleus, chromosome aberration and comet assay endpoints in a 28-day rodent toxicity study with urethane. Mutagenesis 30(3):335-342

Stannard L, Doak SH, Doherty A, Jenkins GJ (2016) Is nickel chloride really a non-genotoxic carcinogen? Basic Clin Pharmacol Toxicol. https://doi.org/10.1111/bcpt.12689

Stewart B, Wild CP (2017) World cancer report 2014. Health (N Y)

Thybaud V, Aardema M, Casciano D et al (2007) Relevance and follow-up of positive results in in vitro genetic toxicity assays: an ILSI-HESI initiative. Mutat Res 633(2):67-79

Tilton SC, Siddens LK, Krueger SK et al (2015) Mechanism-based classification of PAH mixtures to predict carcinogenic potential. Toxicol Sci 146(1):135-145

Tsai JH, Yang J (2013) Epithelial-mesenchymal plasticity in carcinoma metastasis. Genes Dev 27(20):2192-2206

Uehara T, Hirode M, Ono A et al (2008) A toxicogenomics approach for early assessment of potential non-genotoxic hepatocarcinogenicity of chemicals in rats. Toxicology 250(1):15-26. https:// doi.org/10.1016/j.tox.2008.05.013

Willems E, Leyns L, Vandesompele J (2008) Standardization of realtime PCR gene expression data from independent biological replicates. Anal Biochem 379(1):127-129

Williams GM (2001) Mechanisms of chemical carcinogenesis and application to human cancer risk assessment. Toxicology 166(1-2):3-10

Wu S, Powers S, Zhu W, Hannun YA (2016) Substantial contribution of extrinsic risk factors to cancer development. Nature 529(7584):43-47 